\title{
Experimental colitis is ameliorated by inhibition of nitric oxide synthase activity
}

\author{
D Rachmilewitz, F Karmeli, E Okon, M Bursztyn
}

\begin{abstract}
Enhanced nitric oxide (NO) generation by stimulated NO synthase (NOS) activity may, through its oxidative metabolism contribute to tissue injury in experimental colitis. In this study the possible amelioration of experimental colitis by $\mathbf{N}^{\mathbf{G}}$-nitro-Larginine methyl ester (L-NAME), an inhibitor of NOS activity, was evaluated. Colitis was induced in rats by intracolonic administration of $30 \mathrm{mg}$ trinitrobenzene sulphonic acid (TNB) dissolved in $0.25 \mathrm{ml}$ $50 \%$ ethanol or by flushing the colon of capsaicin pretreated rats with $2 \mathrm{ml}$ of $5 \%$ acetic acid. In several experiments, L-
\end{abstract} NAME $0.1 \mathrm{mg} / \mathrm{ml}$ was added to the drinking water at the time of colitis induction with TNB or seven days before acetic acid treatment. Rats were killed at various time intervals after induction of colitis. A $10 \mathrm{~cm}$ distal colonic segment was isolated, weighed, lesion area measured, and explants organ cultured for 24 hours for determination of NO generation by the Greiss reaction. The rest of the mucosa was scraped for determination of myeloperoxidase and NOS activities and leukotriene generation. In TNB treated rats mean arterial pressure was also determined up to 72 hours after damage induction, with or without cotreatment with nitroprusside. L-NAME significantly decreased the extent of tissue injury in TNB treated rats. Seven days after TNB treatment lesion area was reduced by $55 \%$, colonic weight by $37 \%$, and myeloperoxidase and NOS activity by $59 \%$ and $42 \%$, respectively. Acetic acid induced colitis in capsaicin pretreated rats was also significantly decreased by L-NAME. Twenty four hours after acetic acid treatment lesion area was reduced by $61 \%$, colonic weight by $21 \%$, and NOS activity by $39 \%$. Mean (SEM) arterial blood pressure in TNB+L-NAME treated rats was $37.6(8 \cdot 1)$ mm $\mathrm{Hg}$ higher than in TNB treated rats, an effect that was only partially abolished by nitroprusside. These results show that inhibition of NO synthesis by an L-arginine analogue significantly ameliorates the extent of tissue injury in two models of experimental colitis, an effect that is not due only to its vasoconstrictor properties. Modulation of NO generation may be a novel therapeutic approach in inflammatory bowel disease.

(Gut 1995; 37: 247-255)

Keywords: nitric oxide, acetic acid colitis, trinitrobenzene sulphonic acid colitis.
Nitric oxide (NO) has been implicated in diverse biological functions, mediation of macrophage function being one of them. ${ }^{1}$ Basal NO synthase (NOS) activity in macrophages is negligible but, once stimulated by bacterial products or cytokines, NO generation is significantly increased. ${ }^{2} \mathrm{NO}$ generation by activated macrophages has an important role in the defence against infectious agents as well as tumour cells. ${ }^{13}$ When actively produced in large amounts, however, NO may induce tissue injury due to its combination with superoxide anion yielding peroxynitrite. We have shown in rats that intracolonic administration of peroxynitrite induces significant colonic injury. ${ }^{4}$

Recently, in patients with inflammatory bowel disease, colonic NO generation ${ }^{5}$ and NOS activity ${ }^{5}$ were reported to be stimulated. Moreover, stimulated colonic NOS activity was reported in the rat model of trinitrobenzene sulphonic acid (TNB) induced colitis ${ }^{7}$ and NO generation was found to be increased in TNB induced ileitis in guinea pigs. ${ }^{8}$ It is thus suggested that increased NO generation by stimulated NOS activity may contribute to the pathogenesis of experimental colitis and inflammatory bowel disease. Inhibition of NOS activity may, therefore, ameliorate the extent of tissue inflammation and may be used as a novel therapeutic modality in inflammatory bowel disease patients. Analogue of Larginine such as $\mathrm{N}^{\mathrm{G}}$-nitro-L-arginine methyl ester (L-NAME) and $N^{G}$-monomethyl-L-arginine (L-NMMA) are potent inhibitors of NOS activity and L-NAME was shown to ameliorate the extent of TNB induced ileitis on guinea pigs. ${ }^{8}$ The mechanism, however, whereby L-NAME induces its effect and, especially, its potent vasoconstricting effects in this setting was not established.

The aim of this study was to further evaluate the possible contribution of NO to the pathogenesis of several models of experimental colitis and to assess their possible amelioration through potent inhibition of NOS activity.

\section{Methods}

Materials

L-arginine, L-citrulline, $\mathrm{N}^{\mathrm{W}}$-nitro-L-arginine (NNA), L-NAME, L-NMMA, NADPH, calcium ionophore, lipopolysaccharide, dithiothreitol, phenylmethylsulphonyl fluoride, EDTA, and EGTA were purchased from Sigma Chemical, St Louis, MO, USA; Dowex AG50W-X8 (Na form) 100-200 mesh, and TRIS base (electrophoresis grade) were purchased from Bio-Rad Labs, Richmond, 
CA, USA; sodium nitrite and sodium nitrate were obtained from Fisher Chemical, Fair Lawn, NJ, USA; opti-fluor was purchased from Packard, the Netherlands; sulphanilamide and $N$-1-naphthylethylene diamine hydrochloride were purchased from Aldrich Chemical, Milwaukee, MI, USA; TNB was purchased from Eastman Kodak, Rochester, NY, USA; rat recombinant interferon $\gamma$ (IFN $\gamma)$ was purchased from Gibco BRL, Gaithersburg, MD, USA; nitroprusside was purchased from Hoffman-La Roche, Basle, Switzerland; ${ }^{3} \mathrm{H}$-citrulline, leukotriene $\mathbf{B}_{4}$ $\left(\mathrm{LTB}_{4}\right)$, leukotriene $\mathrm{C}_{4}\left(\mathrm{LTC}_{4}\right)$, radioimmunoassay, were purchased from Amersham, Bucks, UK.

\section{Animals \\ Male, Sprague-Dawley rats, weighing 200- $250 \mathrm{~g}$ and fed ad libitum were used in all the studies. All the animal studies described adhere to the standards established by the Guide for The Care and Use of Laboratory Animals. ${ }^{9}$}

\section{TNB induced colitis}

Inflammation of the colon was induced under light ether anaesthesia by a single intracolonic administration of $0.25 \mathrm{ml}$ of $50 \%$ ethanol containing $30 \mathrm{mg}$ of TNB, as previously described. ${ }^{10}$ The solution was introduced through a catheter with a $0.3 \mathrm{~mm}$ outer diameter placed $7 \mathrm{~cm}$ from the anus. Control rats were treated with the vehicle. In several experiments L-NAME $(0 \cdot 1 \mathrm{mg} / \mathrm{ml})$ was added to the drinking water immediately after TNB or vehicle administration. Daily water consumption was monitored per cage with five rats uniformly treated. Drinking behaviour was similar in control and L-NAME treated rats. Estimated daily L-NAME consumption was $30 \mathrm{mg} / \mathrm{kg}$. This oral route of L-NAME administration was previously shown to induce systemic inhibition of NOS activity. ${ }^{11}$ Rats were killed one, three, and seven days after the induction of colonic injury. The colon was isolated, placed unstretched on a ruler, and a $10 \mathrm{~cm}$ segment of distal colon was resected, its lumen rinsed with ice cold saline and weighed. Tissue samples from the most damaged site were obtained for histological assessment and several sections along the $10 \mathrm{~cm}$ segment were taken for organ culture. In different rats the mucosa was scraped and samples were processed for determination of lipoxygenase products, myeloperoxidase, and NOS activities.

\section{Determination of mean arterial pressure}

In several experiments rats were anaesthetised with ether and a PE-50 cannula was inserted through the femoral artery into the abdominal aorta and exteriorised subcutaneously at the interscapular area. Cannulas were filled with heparinised saline solution $(100 \mu \mathrm{U} / \mathrm{ml})$ and rats were housed individually. Mean arterial pressure was recorded 24 hours after recovery by use of P23 Statham-Gould transducers (Gould, Oxnard, CA, USA) and recorded on Gould physiograph (model 13-34615-52) after 10-20 minutes of equilibration while rats were moving freely in their cages. Mean arterial pressure was measured before, 24,48 , and 72 hours after TNB treatment and during LNAME administration to the drinking water. In another group of rats after the basal mean arterial pressure measurement, under ether anaesthesia, an osmotic minipump (Alzet, Palo Alta, CA, USA) was implanted intraperitoneally delivering nitroprusside, $0.42 \mu \mathrm{g} / \mathrm{min}$.

\section{Acetic acid induced colitis}

Acetic acid colitis was induced in control rats and also two weeks after completion of capsaicin treatment in which rats were treated subcutaneously with capsaicin in increasing doses $(20,30$, and $50 \mathrm{mg} / \mathrm{kg}$ ) on three consecutive days in a regimen shown to deplete neuropeptides in primary afferent neurons. ${ }^{12}$ In several experiments L-NAME $0.1 \mathrm{mg} / \mathrm{ml}$ was added to the drinking water seven days before, or at the time of colitis induction. Under light ether anaesthesia a midline abdominal incision was made and the junction of the caecum and ascending colon identified. Two $\mathrm{ml}$ of $5 \%$ acetic acid were injected into the lumen of the colon at its proximal part through a 25 gauge needle, followed by $3 \mathrm{ml}$ of air, which cleared most of the acetic acid from the colon. The midline incision was closed. Twenty four hours later the rats were killed and their colons removed and handled, as with the TNB model.

\section{Determination of mucosal damage}

Mucosal damage was measured macroscopically and expressed in $\mathrm{mm}^{2} / \mathrm{rat}$. All measurements of damage were performed by two blinded observers using a stereomicroscope. The interobserver variability between the two observers was $7 \%$.

\section{Organ culture}

Colonic explants were kept in $\mathrm{NaCl} 0 \cdot 15 \mathrm{M}$ at $4^{\circ} \mathrm{C}$ and within 15 minutes after excision were cultured as previously described. ${ }^{13}$ In brief, the tissue was weighed, oriented on metal grids, and organ cultured for 24 hours at $37^{\circ} \mathrm{C}, 95 \%$ $\mathrm{O}_{2}, 5 \% \mathrm{CO}_{2}$ in AIM-V medium (Gibco) containing penicillin and gentamicin.

\section{Measurement of NO production}

$\mathrm{NO}$, quantified by the accumulation of oxides of nitrogen $\left(\mathrm{NO}_{\mathrm{x}}\right)$ in the culture medium, was measured spectrophotometrically using the Greiss reaction, ${ }^{14}$ with sodium nitrite dissolved in the organ culture medium as a standard. Each determination was controlled to subtract any possible interference of the medium. Briefly, $50 \mu$ l of culture supernatants were mixed with equal volume of $1 \%$ sulphanilamide in $0.5 \mathrm{~N} \mathrm{HCl}$. After five minutes, $50 \mu \mathrm{l}$ of $0.02 \% N-1$-naphthylethylene diamine 
dihydrochloride were added and 10 minutes later, absorbency was measured at $540 \mathrm{~nm}$.

\section{Determination of NOS activity}

NOS activity was monitored by the conversion of $\left[{ }^{3} \mathrm{H}\right]$-L-arginine to citrulline according to Bush et al. ${ }^{15}$ Mucosal scrapings $(100 \mathrm{mg})$ were homogenised for 30 seconds at $4^{\circ} \mathrm{C}$ with a polytron (Kinematica $\mathrm{GmbH}$, Kriens-Luzern, Switzerland) in $0.3 \mathrm{ml}$ of ice cold $50 \mathrm{mM}$ TRIS $\mathrm{HCl}, \mathrm{pH} 7 \cdot 4$ containing $0 \cdot 1 \mathrm{mM}$ EDTA, $0 \cdot 1$ $\mathrm{mM}$ EGTA, $0.5 \mathrm{mM}$ dithiothreitol, $1 \mathrm{mM}$ phenylmethylsulphonyl fluoride. Homogenates were centrifuged at $20000 \times g$ for 60 minutes at $4^{\circ} \mathrm{C}$ and the supernatant was used as the source of NOS. Enzymatic reactions were conducted at $37^{\circ} \mathrm{C}$ in $50 \mathrm{mM}$ TRIS $\mathrm{HCl}$, pH $7 \cdot 4$ containing $100 \mu \mathrm{M}$ L-arginine, 100 $\mu \mathrm{M}$ NADPH, $2 \mathrm{mM} \mathrm{CaCl}, 0.2-0.4 \mathrm{mg}$ supernatant proteins, other test agents as indicated, and approximately $200000 \mathrm{dpm}$ of $\mathrm{L}-\left[2,3,4,5-{ }^{3} \mathrm{H}\right]$-arginine $\mathrm{HCl}(77 \mathrm{Ci} / \mathrm{mmol}$; Amersham, UK) to a final volume of $100 \mu \mathrm{l}$. Enzymatic reactions were terminated by addition of $2.0 \mathrm{ml}$ of ice cold 'stop buffer': twenty $\mathrm{mM}$ sodium acetate, $\mathrm{pH} 5 \cdot 5,1 \mathrm{mM}$ Lcitrulline, $2 \mathrm{mM}$ EDTA, and $0 \cdot 2 \mathrm{mM}$ EGTA. Citrulline was determined by applying the samples $(2.0 \mathrm{ml})$ prepared as described above, to columns ( $1 \mathrm{~cm}$ diameter) containing $1 \mathrm{ml}$ of Dowex AG50W[X8, Na form, which had been pre-equilibrated with stop buffer. Columns were eluted with $4 \times 1.0 \mathrm{ml}$ of water collected into scintillation vials. Opti-fluor $(10 \mathrm{ml})$ was added to each vial and samples were counted in a Packard Tri-Carb liquid scintillation spectrometer. Citrulline was recovered in the first $4.0 \mathrm{ml}$ of the Dowex column eluate to the extent of $96(2) \%$. Interassay variation is 1.0 $(1.9) \%$ (mean (SEM); $n=55)$.

\section{Determination of myeloperoxidase activity}

Two hundred mg of colonic mucosal scrapings were homogenised three times for 30 seconds at $4^{\circ} \mathrm{C}$ with a polytron (Kinematica $\mathrm{GmbH}$, Kriens-Luzern, Switzerland) in $1.0 \mathrm{ml}$ of ice cold $0.5 \%$ hexadecyltrimethylammonium bromide in $50 \mathrm{mM}$ phosphate buffer, $\mathrm{pH} 6.0$. The polytron probe was rinsed twice with $1 \cdot 0$ $\mathrm{ml}$ of the buffer and the washings were added to the homogenate. The homogenate was then sonicated for 10 seconds, freeze thawed three times, and centrifuged for 15 minutes at $40000 \mathrm{~g}$. An aliquot of the supernatant was taken for determination of the enzyme activity, according to Bradley et al. ${ }^{16}$ The correlation coefficient based on 10 standard curves is $r=0.98$. Interassay variation is $0(1.65) \%$ (mean (SEM); $\mathrm{n}=57$ ).

\section{Determination of lipoxygenase products}

One hundred and fifty mg of mucosa were placed in preweighed tubes containing $1.0 \mathrm{ml}$ of phosphate buffer $(50 \mathrm{mM}, \mathrm{pH} 7 \cdot 4)$. The mucosa was minced with scissors and centrifuged in an Eppendorf centrifuge for 10 seconds. The pellet was resuspended in $1.0 \mathrm{ml}$ of the above buffer, incubated for one minute in a vortex mixer, indomethacin added, and the tubes centrifuged for 60 seconds. The supernatants were kept at $-20^{\circ} \mathrm{C}$ until radioimmunoassays were performed. The capability of the mucosa to generate $\mathrm{LTB}_{4}$ and $\mathrm{LTC}_{4}$ was expressed as ng/g wet tissue weight.

\section{Measurement of $\mathrm{LTB}_{4}$}

$\mathrm{LTB}_{4}$ immunoreactivity was determined by a radioimmunoassay kit (Amersham, TRK 940). The assay combines the use of a high specific activity $\mathrm{LTB}_{4}$ tracer, an antiserum specific for $\mathrm{LTB}_{4}$ (cross reactivity $100 \%$ ), and a leukotriene standard (range 1.6 to $200 \mathrm{pg} /$ tube). The specific binding of tracer is $42.5 \%$, nonspecific binding $2 \cdot 4 \%$. Fifty per cent $\mathrm{B} / \mathrm{Bo}$ displacement is obtained with $15 \mu \mathrm{g} /$ tube and $90 \%$ $\mathrm{B} / \mathrm{Bo}$ displacement with $2 \cdot 2 \mathrm{pg} /$ tube of $\mathrm{LTB}_{4}$. The percentage coefficient of variation $(\mathrm{CV})$ for within assay precision ranges from $8 \cdot 2$ (low) to 8.6 (high). The percentage CV for the precision profile of the assay ranges from 2.3 to 6.35 $(n=10)$. The percentage $B / B o$ for between assay reproducibility ranges from 92 to 5.9 (standard $1 \cdot 5-200 \mathrm{pg} /$ tube; $\mathrm{n}=10$ ).

\section{Measurement of $\mathrm{LTC}_{4}$}

$\mathrm{LTC}_{4}$ immunoreactivity was determined by radioimmunoassay. The assay combines the use of a high specific activity LTC $_{4}$ tritiated tracer with a monoclonal antibody specific for $\mathrm{LTC}_{4}$ and $\mathrm{LTC}_{4}$ standard (8-500 pg/tube). The assay uses highly specific $\mathrm{LTC}_{4}$ antiserum (cross reactivity $=100 \%$ ) and has low cross reactivity with leukotriene $\mathrm{D}_{4}\left(\mathrm{LTD}_{4}\right)(<5 \%)$. The specific binding of tracer is $40 \%-45 \%$ and non-specific binding is $1 \%-3 \%$. Fifty per cent $\mathrm{B} / \mathrm{Bo}$ displacement is obtained with 34 $\mathrm{pg} /$ tube, and $80 \% \mathrm{~B} /$ Bo displacement with 9.5 $\mathrm{pg} /$ tube of $\mathrm{LTC}_{4}$. The percentage $\mathrm{CV}$ for within assay precision ranges from 7.68 (low) to 3.94 (high). The percentage $\mathrm{CV}$ for the precision profile of the assay ranges from 1.64 to $3.49(n=9)$. The percentage $B / B o$ for between assay reproducibility ranges from 87 to $5 \cdot 4$ (standard $8-800 \mathrm{pg} /$ tube; $\mathrm{n}=9$ ).

\section{Morphological studies}

Sections of colon were obtained from the same areas of the large intestine during necropsy. They were fixed in phosphate buffered formaldehyde, embedded in paraffin wax, and routine $5 \mu \mathrm{m}$ sections were prepared. Tissues were routinely stained with haematoxylin and eosin and were evaluated by light microscopy by a pathologist unaware of the experiments being performed. As the histological features of the $\mathrm{TNB}^{10}$ and acetic acid ${ }^{17}$ induced colitis were previously reported by us, only the histology of the new acetic acid augmented colitis in capsaicin pretreated rats is reported in detail.

\section{Statistical analysis}

Data are expressed as mean (SEM). Statistical 
TABLE I Effect of L-NAME on colonic lesions and weight in TNB induced colitis

\begin{tabular}{|c|c|c|c|c|c|c|c|}
\hline Treatment & \multicolumn{3}{|l|}{$T N B$} & \multicolumn{3}{|c|}{$T N B+L-N A M E$} & \multirow[t]{2}{*}{ None } \\
\hline $\begin{array}{l}\text { Time (days) } \\
\text { Lesions }\left(\mathrm{mm}^{2} / \mathrm{rat}\right)\end{array}$ & 1 & 3 & 7 & 1 & 3 & 7 & \\
\hline Number & 17 & 14 & 12 & 5 & 9 & 5 & 21 \\
\hline Mean (SEM) & $913(117)$ & $702(53)$ & $773(84)$ & $650(200)$ & $384(102)^{\star}$ & $349(195)^{\star}$ & 0 \\
\hline Median & 780 & 698 & 710 & 576 & 592 & 98 & \\
\hline $\begin{array}{l}\text { Range } \\
\text { Weight }(\mathrm{g} / 10 \mathrm{~cm})\end{array}$ & $276-1840$ & $300-950$ & $300-1600$ & $78-1235$ & $0-720$ & 0-966 & \\
\hline Number & 8 & 14 & 18 & 5 & 8 & 5 & 21 \\
\hline Mean (SEM) & $1.90(0.13)$ & $2 \cdot 20(0 \cdot 10)$ & $2 \cdot 30(0 \cdot 10)$ & $1 \cdot 23(0 \cdot 12)^{\star}$ & $1.33(0.10)^{\star}$ & $1.68(0.30)^{\star}$ & $0.61(0.02)$ \\
\hline Median & 1.98 & $2 \cdot 30$ & $2 \cdot 25$ & $1 \cdot 12$ & 1.33 & $1 \cdot 24$ & 0.59 \\
\hline Range & $1 \cdot 24-2 \cdot 33$ & $1 \cdot 38-2 \cdot 84$ & $1 \cdot 56-3 \cdot 53$ & $0.93-1.56$ & $0 \cdot 89-1 \cdot 82$ & $1 \cdot 19-2 \cdot 67$ & $0 \cdot 48-0.78$ \\
\hline
\end{tabular}

Lesion area and weight of the $10 \mathrm{~cm}$ distal colonic segment of rats treated with TNB with or without addition of L-NAME to the drinking water were determined as described in Methods. ${ }^{\star}$ Significantly different from TNB $(\mathrm{p}<0.05)$.

analysis for significant differences was performed according to the Student's $t$ test for paired data and the non-parametric MannWhitney $U$ test. Mean arterial pressure measurements were analysed with the two way analysis of variance with the post hoc A Newman-Keuls test. The Crunch statistical package (Crunch Software, 4th revision, 1991, Oakland, CA, USA) was used for comparison between the different treatment groups.

\section{Results}

Effect of $L-N A M E$ on TNB induced colitis Intracolonic administration of TNB/ethanol resulted in extensive haemorrhagic and ulcerative damage to the distal colon, as we reported previously. ${ }^{10}$ By 24 hours the damage was localised with a lesion area of 913 (117) $\mathrm{mm}^{2}$ $(n=17$; mean $($ SEM $)$ ). Three and seven days after damage induction the lesion area was smaller but not significantly different from that seen after 24 hours (Table I). The addition of L-NAME to the drinking water induced a significant decrease in the lesion area, but this was noted only three and seven days after damage induction (Table I). The amelioration of the severity of the inflammatory response in L-NAME treated rats was also reflected by the significant difference in the wet weight of the $10 \mathrm{~cm}$ long distal colonic segment in L-NAME and control rats treated with $\mathrm{TNB} /$ ethanol (Table I). At all time intervals colonic myeloperoxidase activity in TNB treated rats was several fold higher than its activity in control rats. In L-NAME + TNB treated rats, myeloperoxidase activity three and seven days after TNB treatment was $40 \%$ of its activity in rats treated only with TNB (Fig 1). In nitroprusside treated rats mucosal myeloperoxidase activity was $0.5(0.4) \mathrm{u} / \mathrm{g}$, similar to its activity in control rats. In TNB treated rats, one and three days after its administration, mucosal $\mathrm{LTB}_{4}$ generation was significantly increased when compared with its generation in control

TABLE II Effect of L-NAME on colonic leukotriene generation in TNB induced colitis

\begin{tabular}{llllllll}
\hline Treatment & None & TNB & & \multicolumn{5}{l}{ TNB+L-NAME } \\
\hline Time (days) & & 1 & 3 & 7 & 1 & 3 & 7 \\
Number & 7 & 9 & 7 & 7 & 5 & 8 & 7 \\
LTB $_{4}$ (ng/g) & $1 \cdot 5(0 \cdot 4)$ & $6 \cdot 6(1 \cdot 0)^{\star}$ & $3 \cdot 4(0 \cdot 5)^{\star}$ & $5 \cdot 2(1 \cdot 7)$ & $3 \cdot 8(0 \cdot 8)$ & $3 \cdot 1(0 \cdot 5)$ & $2 \cdot 7(0 \cdot 3)$ \\
LTC $_{4}$ (ng/g) & $2 \cdot 4(0 \cdot 1)$ & $3 \cdot 1(0 \cdot 8)$ & $5 \cdot 1(0 \cdot 9)^{\star}$ & $4 \cdot 0(0 \cdot 4)^{\star}$ & $2 \cdot 0(0 \cdot 4)$ & $4 \cdot 0(0 \cdot 8)$ & $3 \cdot 7(0 \cdot 6)$ \\
\hline
\end{tabular}

Mucosal $\mathrm{LTB}_{4}$ and $\mathrm{LTC}_{4}$ generation in the $10 \mathrm{~cm}$ distal colonic segment of rats treated with TNB with or without addition of L-NAME to the drinking water was determined as described in Methods. Results are mean (SEM). *Significantly different from no treatment $(p<0 \cdot 05)$. rats. Mucosal $\mathrm{LTC}_{4}$ generation was significantly increased three and seven days after damage induction. In TNB +L-NAME treated rats mucosal leukotriene generation was lower than in TNB treated rats, but the difference was not statistically significant (Table II).

The accumulation of $\mathrm{NO}_{\mathrm{x}}$ in the medium of cultured colonic segments isolated from control rats increased with time: $14.5(5 \cdot 7)(n=6)$, $39.2(14.0)(n=4)$, and $258.0(27 \cdot 0)(n=22)$ $\mu \mathrm{mol} / \mathrm{g}$ wet weight after four, eight, and 24 hours, respectively. The small standard errors of colonic $\mathrm{NO}_{\mathrm{x}}$ generation during 24 hour culture of six explants obtained from the same normal rat 196 (25) $\mu \mathrm{mol} / \mathrm{g}$ (mean (SEM)) show that explant sampling was reproducible. $\mathrm{NO}_{\mathrm{x}}$ generation by inflamed colonic segments isolated 24 hours after TNB treatment was 11fold higher than by explants isolated from control rats: $2236(320)(\mathrm{n}=12)$ and 204 (36) $(\mathrm{n}=19) \mu \mathrm{mol} / \mathrm{g} / 24 \mathrm{~h}$, respectively.

One, three, and seven days after TNB treatment colonic NOS activity was 4.5-, 22-, and 18-fold higher, respectively, than in control rats. In TNB+L-NAME treated rats, three and seven days after treatment, NOS activity was significantly lower than in TNB treated rats (Fig 2).

Effect of L-NAME on mean arterial pressure Figure 3 shows mean arterial pressure measurements in the various treatment groups.

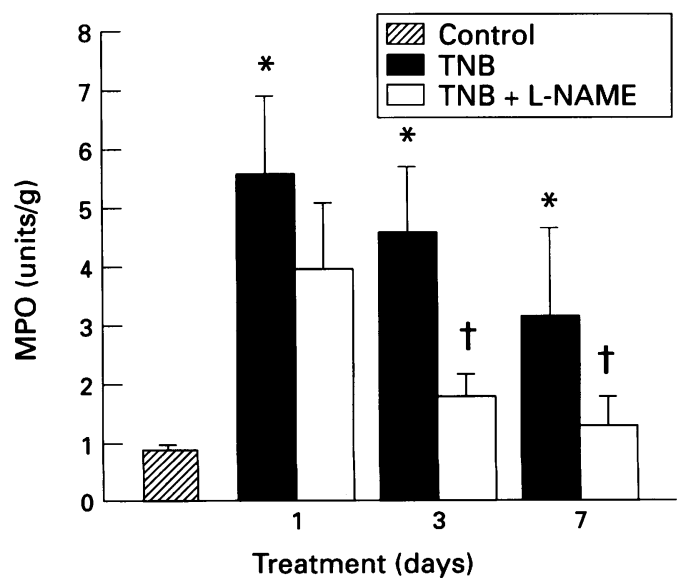

Figure 1: Effect of L-NAME on colonic myeloperoxidase activity in TNB treated rats. Colonic myeloperoxidase activity was determined one, three, and seven days after colonic TNB administration to control and L-NAME treated rats, as described in Methods. Results are mean (SEM). * Significantly different from control $(p<0.05)$. + Significantly different from TNB treated rats $(p<0.05)$. 


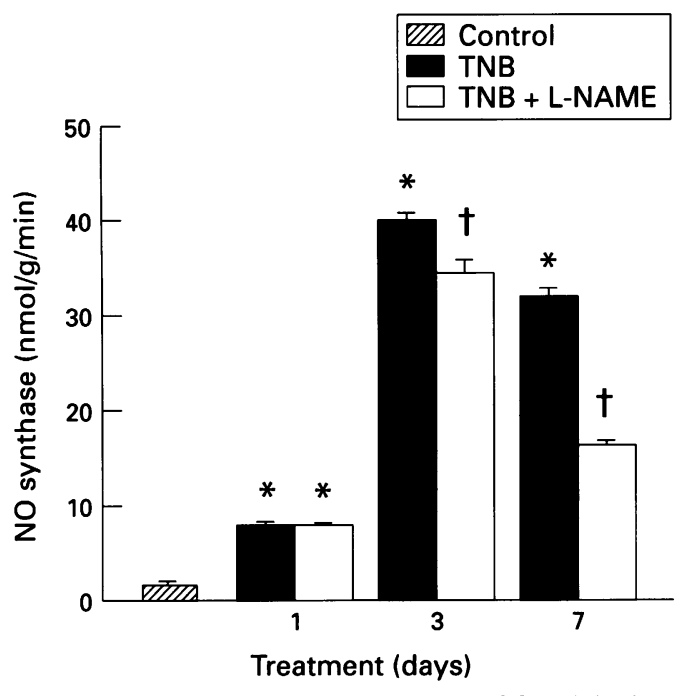

Figure 2: Effect of L-NAME on colonic NOS activity in TNB treated rats. Colonic NOS activity was determined one, three, and seven days after colonic TNB administration, as described in Methods. * Significantly different from control $(p<0 \cdot 05)$. + Significantly different from $T N B(p<0 \cdot 05)$.

L-NAME induced in TNB treated rats a significant increase in mean arterial pressure of $37.6(8.1) \mathrm{mm} \mathrm{Hg}$, compared with mean arterial pressure in rats treated only with TNB $(p<0.05)$. Two way analysis of variance indicated differences among mean arterial pressure curves shown in Fig $3, F(4 ; 16)=18.8$, $\mathrm{p}<0 \cdot 005$. Post hoc analysis showed that the highest curve was in the TNB+L-NAME, specifically greater than that in the $\mathrm{TNB}+\mathrm{L}-$ NAME + nitroprusside group $(p<0.02)$, showing that nitroprusside attenuated the L-NAME induced hypertension as the TNB and TNB + L-NAME+ nitroprusside curves did not differ. The TNB+nitroprusside curve was significantly lower than that in TNB alone $(p<0.008)$, however, pointing to the hypotensive efficacy of nitroprusside. Nitroprusside

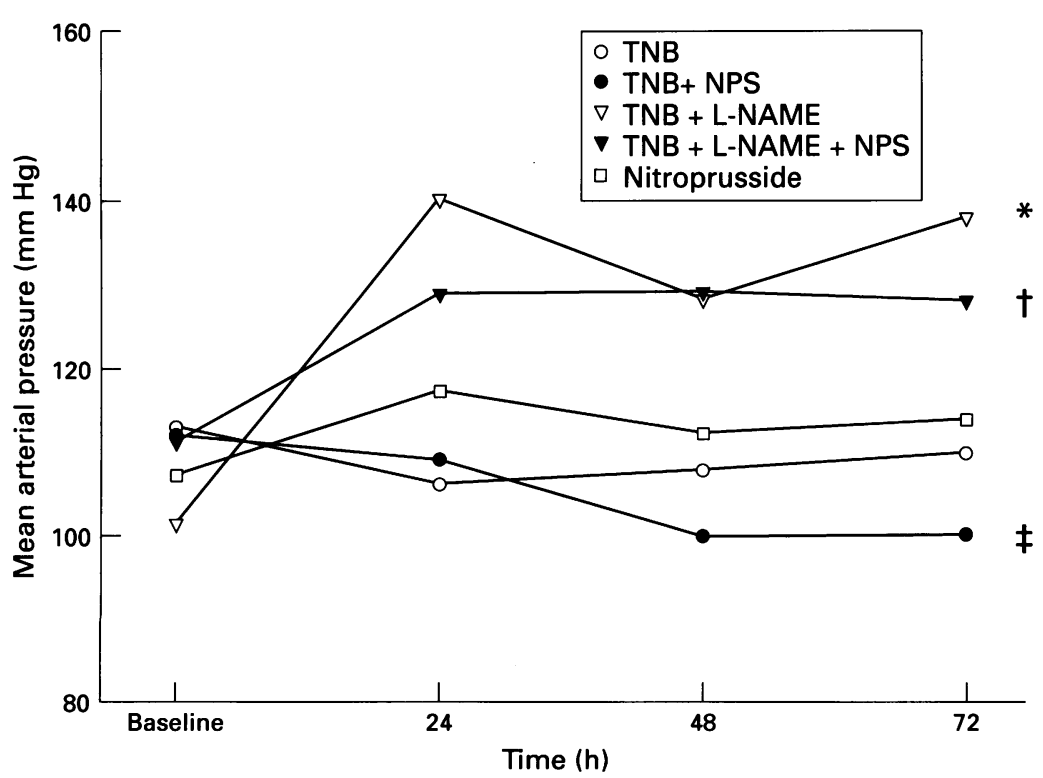

Figure 3: Line graph showing baseline, 24, 48, and 72 hours mean intra-arterial blood pressure in TNB treated rats, TNB+nitroprusside, $T N B+L-N A M E$

$T N B+L-N A M E+N P S$, and NPS alone. Two way ANOVA between the groups shows significance $\mathrm{F}(4 ; 16)=18.8, p<0 \cdot 004 . \star=T N B+L-N A M E \mathrm{v}$ all other groups, $p<0.02$ $\dagger=T N B+L-N A M E+N P S$ v TNB and TNB+nitroprusside, $p<0 \cdot 01 . \ddagger=T N B+$ nitroprusside $\mathrm{v} T N B, p<0 \cdot 01$.
TABLE III Effect of nitroprusside and L-NAME on TNB induced colitis

\begin{tabular}{lccl}
\hline Treatment & Number & $\begin{array}{l}\text { Lesion area } \\
\left(\mathrm{mm}^{2}\right)\end{array}$ & $\begin{array}{l}\text { Wet weight } \\
(\mathrm{g})\end{array}$ \\
\hline None & 21 & 0 & $0 \cdot 60(0 \cdot 02)$ \\
Nitroprusside & 3 & 0 & $0 \cdot 80(0 \cdot 04)$ \\
L-NAME & 9 & 0 & $0 \cdot 70(0 \cdot 04)$ \\
TNB & 14 & $702(53)$ & $2 \cdot 2(0 \cdot 1) \dagger$ \\
TNB+L-NAME & 8 & $384(102)$ & $1 \cdot 3(0 \cdot 1)$ \\
$\begin{array}{l}\text { TNB+L-NAME+ } \\
\quad \text { nitroprusside }\end{array}$ & 4 & $807(329)^{\star}$ & $2 \cdot 0(0 \cdot 3)^{\star}$ \\
\hline
\end{tabular}

Colitis was induced by intracolonic TNB administration. Rats were treated with L-NAME $(0 \cdot 1 \mathrm{mg} / \mathrm{ml})$ added to the drinking water. One of the groups also received intraperitoneal nitroprusside $(0.42 \mu \mathrm{g} / \mathrm{ml})$. Another group was treated only with nitroprusside $(0.42 \mu \mathrm{g} / \mathrm{ml})$. Rats were killed after 72 hours. Lesion area and the wet weight of the $10 \mathrm{~cm}$ distal colonic segment were measured. ${ }^{*}$ Significantly different from TNB+L-NAME $(p<0 \cdot 05)$. †Significantly different from no treatment $(p<0.05)$. Results are mean (SEM).

treatment did not induce any injury but abolished the protective effect of L-NAME on the extent of tissue injury induced by TNB. L-NAME, by itself, did not induce any macroscopic injury (Table III).

Effect of L-NAME on acetic acid induced colitis Twenty four hours after administration of acetic acid the colon was haemorrhagic and inflamed. The lesion area, and the wet weight of the $10 \mathrm{~cm}$ long distal colonic segment in capsaicin pretreated rats were 3 - and $1 \cdot 5$-fold higher, respectively, than in rats treated only with acetic acid (Table IV). The addition of L-NAME to the drinking water significantly reduced the extent of the augmented acetic acid injury in capsaicin pretreated rats (Table IV). Mucosal myeloperoxidase activity in control, acetic acid, and capsaicin +acetic acid treated rats was $0.9(0.1)(n=10), 3.5$ $(0 \cdot 7)(n=10)$, and $15.8(4 \cdot 4)(n=6) \mathrm{U} / \mathrm{g}$, respectively. L-NAME did not significantly affect mucosal $\mathrm{LTB}_{4}$ and $\mathrm{LTC}_{4}$ generation in control rats. Both in acetic acid and in capsaicin +acetic acid treated rats colonic $\mathrm{LTB}_{4}$ generation was significantly increased when compared with its generation in control rats. The amelioration of the extent of the colonic damage in L-NAME treated rats was accompanied by significant decrease in mucosal $\mathrm{LTB}_{4}$ generation (Fig 4). Mucosal $\mathrm{LTC}_{4}$ generation was significantly increased only in acetic acid treated rats. Its generation in capsaicin +L-NAME+acetic acid treated rats was significantly lower, however, than in capsaicin + acetic acid treated rats (Fig 4).

In acetic acid treated rats colonic $\mathrm{NO}_{\mathrm{x}}$ generation by cultured explants and colonic NOS activity were three- and twofold higher, respectively, than in normal colonic mucosa (Fig 5). The augmentation of acetic acid induced colitis in capsaicin pretreated rats is accompanied by further increase in $\mathrm{NO}_{\mathrm{x}}$ generation and NOS activity. On the other hand, both $\mathrm{NO}_{\mathrm{x}}$ generation and NOS activity were significantly reduced in L-NAME treated rats when compared with their values in acetic acid + capsaicin treated rats. In control rats, the addition of L-NAME to the drinking water 
TABLE IV Effect of L-NAME on colonic lesions and weight in capsaicin and acetic acid treated rats

\begin{tabular}{lcccc}
\hline Treatment & Acetic acid & $\begin{array}{l}\text { Capsaicin } \\
\text { acetic acid }\end{array}$ & $\begin{array}{l}\text { Capsaicin }+ \text { LAMME+N } \\
\text { acetic acid }\end{array}$ & None \\
\hline $\begin{array}{l}\text { Number } \\
\text { Lesions }\left(\mathrm{mm}^{2}\right)\end{array}$ & 21 & 11 & 9 & 21 \\
Mean (SEM) & $330(38)$ & $1064(128)^{\star}$ & $410(86) \dagger$ & 0 \\
Median & 256 & 1125 & 350 & \\
Range & $105-900$ & $330-1620$ & $150-960$ & \\
Weight $(\mathrm{g} / 10 \mathrm{~cm})$ & & & & $0.61(0.02)$ \\
Mean (SEM) & $0.96(0.04)$ & $1.53(0.09)^{\star}$ & $1.21(0.09) \dagger$ & 0.59 \\
Median & 0.93 & 1.56 & 1.31 & $0.48-0.78$ \\
Range & $0.63-1.52$ & $1.00-2.09$ & $0.84-1.68$ & \\
& & &
\end{tabular}

Lesion area and weight of the $10 \mathrm{~cm}$ distal colonic segment were determined in rats treated with $5 \%$ acetic acid with and without pretreatment with capsaicin and L-NAME, as described in Methods. * Significantly different from acetic acid $(p<0.05)$. + Significantly different from acetic acid+capsaicin $(\mathrm{p}<0.05)$

induced significant decrease in $\mathrm{NO}_{\mathrm{x}}$ generation by cultured mucosa, but had no effect on NOS activity.

\section{Colonic $\mathrm{NO}_{\mathrm{x}}$ generation}

In normal rats, colonic $\mathrm{NO}_{\mathrm{x}}$ generation was inhibited by NNA (Table V). In the presence of calcium ionophore $(1 \mu \mathrm{M}), \mathrm{NO}_{\mathrm{x}}$ generation during 24 hours of culture was 219 (53)\% $(\mathrm{n}=10)$ of its basal generation regarded as $100 \%(\mathrm{p}=0.05 ; t$ test for paired data), indicating the contribution of the constitutive enzyme to NO generation under basal conditions. The stimulation of $\mathrm{NO}_{\mathrm{x}}$ generation in normal colonic mucosa by IFN $\gamma$ indicates expression of the inducible isoform of NOS (Table V).

$\mathrm{NO}_{x}$ generation by inflamed colonic segments was significantly stimulated by lipopolysaccharide and IFN $\gamma$ and significantly inhibited by NNA. The inhibition of $\mathrm{NO}_{\mathrm{x}}$ generation induced by NNA was more pronounced in explants isolated from normal rats than that seen in explants isolated from rats with experimental colitis (Table V). Both in normal rats and in rats with experimental colitis, colonic NOS activity was significantly inhibited by NNA and was NADPH dependent (Table VI).

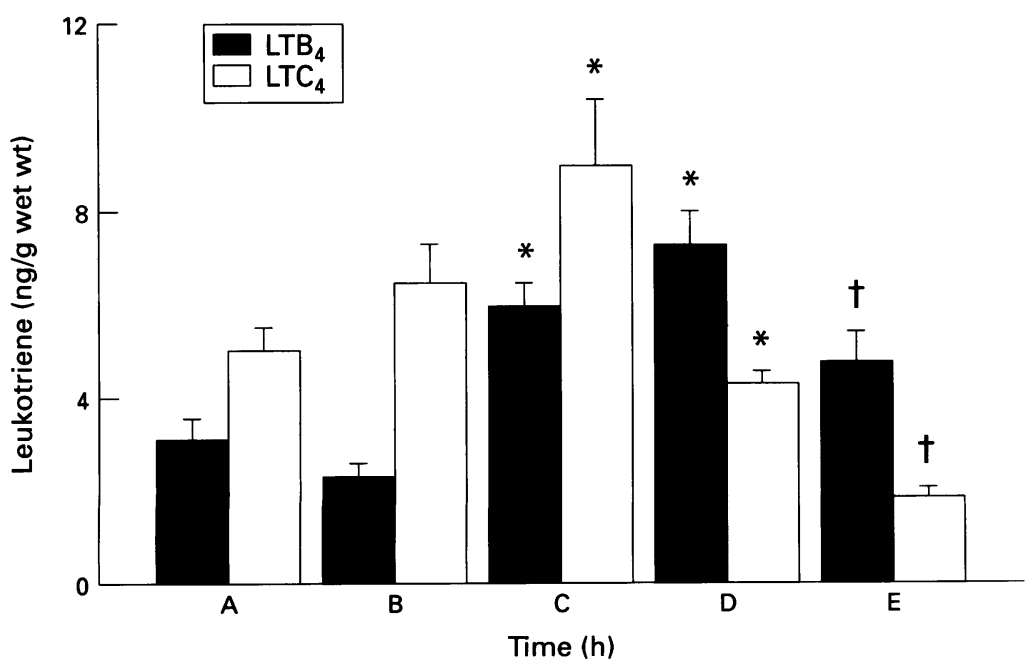

Figure 4: Effect of L-NAME on colonic leukotriene generation in capsaicin + acetic acid treated rats. Colonic $\mathrm{LTB}_{4}$ and $\mathrm{LTC}_{4}$ generation was determined in rats treated with capsaicin +acetic acid with or without administration of L-NAME, as described in $M e t h o d s . A=$ control $B=L-N A M E ; C=$ acetic acid; $D=$ capsaicin + acetic acid; $E=$ capsaicin $+L-N A M E+$ acetic acid. * Significantly different from control $(p<0 \cdot 05)$. †Significantly different from capsaicin + acetic acid treated rats $(p<0 \cdot 05)$.

\section{Histological assessment}

Sections of the large intestine from rats treated with acetic acid showed multiple, full thickness, mucosal ulcerations with moderate oedema of the submucosa, accompanied by moderate inflammatory cell infiltrate (Fig 6(A)). In rats pretreated with capsaicin before acetic acid treatment, there were widespread ulcerations involving the mucosa and submucosa with extensive haemorrhages, oedema and widespread, acute, inflammatory infiltrate. There was pseudomembrane formation as well as foci of inflammation in the muscularis propria (Fig 6(B)). Cross sections of colonic segments from rats treated with L-NAME before damage induction by capsaicin and acetic acid disclosed multiple small ulcerations confined to the mucosa, some involving the full thickness of the mucosa with mild to moderate oedema accompanied by mild to moderate inflammatory infiltrate (Fig 6(C)).

\section{Discussion}

In this study inhibition of NOS activity by LNAME was found to ameliorate the extent and severity of tissue injury in two models of experimental colitis in which colonic $\mathrm{NO}_{\mathrm{x}}$ generation and NOS activity were found to be stimulated. These findings support the concentration that NO participates in the pathogenesis of colonic inflammation augmenting and amplifying the extent of tissue injury.

Inflamed colonic mucosa is characterised by the abundance of activated inflammatory cells, such as macrophages and neutrophils. The activation of these inflammatory cells is expressed in a variety of ways, including synthesis and release of certain cytokines, inflammatory mediators, such as leukotrienes and platelet activating factor, and the release of reactive oxygen metabolites. ${ }^{18}$ Recently, these mediators were also shown to induce NO generation by phagocytic leucocytes. ${ }^{2} 1920$ Moreover, macrophages and inflammatory neutrophils were shown to contain a calcium and calmodulin independent NOS that is activated by agents, such as lipopolysaccharide and IFN $\gamma .{ }^{12}$

$\mathrm{NO}$ is produced from $\mathrm{L}$-arginine by the enzyme, NOS. ${ }^{1}$ The normal colon expresses the constitutive NOS, as shown in this study, by its response to changes in calcium flux. The high $\mathrm{NO}_{\mathrm{x}}$ output response of colonic mucosa to cytokines, for example, IFN $\gamma$, and to lipopolysaccharide, indicates expression of the inducible isoform of NOS in the gut. NO has been proposed as a mediator of bactericidal, tumorstatic, and tumorocidal activity of macrophages. ${ }^{13}$ These last properties are ascribed to the simultaneous generation by macrophages of superoxide and NO, yielding peroxynitrite (OONO·), which decomposes to $\mathrm{OH} \cdot$ and $\mathrm{NO}_{2} \cdot$, or other related decomposing products. OONO and the free radicals, $\mathrm{OH}$. and $\mathrm{NO}_{2} \cdot$, oxidise sulphydryl groups and react with metal ions, ${ }^{21} 22$ and was recently shown by us to induce severe colonic inflammation. ${ }^{4}$ In addition, NO has also immunoregulatory properties, such as inhibition of lymphocyte proliferation. ${ }^{23}$ 


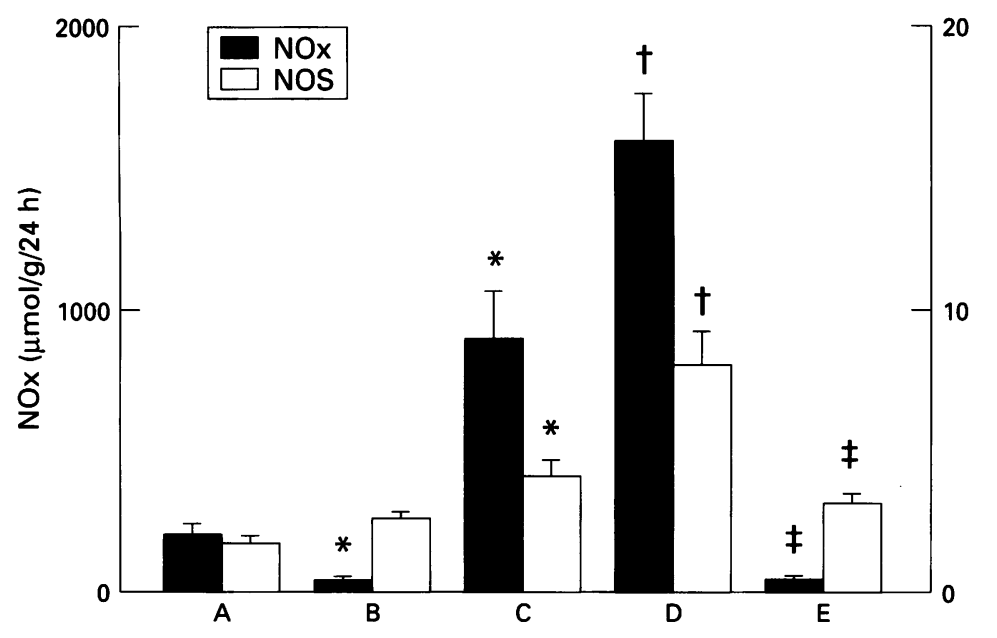

Figure 5: Effect of L-NAME on colonic $N O_{\mathrm{x}}$ generation and NOS activity in capsaicin + acetic acid treated rats. Colonic $N O_{\mathrm{x}}$ generation by cultured explants and colonic NOS activity were determined in rats treated with capsaicin + acetic acid with or without administration of $L-N A M E$, as described in Methods. $A=$ control; $B=L-N A M E$ $C=$ acetic acid; $D=$ capsaicin + acetic acid; $E=$ capsaicin $+L-N A M E+$ acetic acid.

$\star$ Significantly different from control $(p<0 \cdot 05)$. + Significantly different from acetic acid $(p<0 \cdot 05)$. $¥$ Significantly different from capsaicin + acetic acid $(p<0 \cdot 05)$.

The results obtained in this study show that, in two models of experimental colitis, colonic generation of nitrites reflecting NO generation and colonic NOS activity are significantly increased when compared with the respective NO generation and NOS activity of normal colonic mucosa. Nitrites are end products of the oxidative metabolism of the labile NO in vivo and their quantification is regarded as an indicator of NO generation. ${ }^{14}$ Recently, plasma concentrations of nitrites was found to be increased three weeks after induction of granulomatous colitis by intramural injection of peptidoglycan-polysaccharide into the distal colon of genetically susceptible rats ${ }^{24}$ and the nitrite concentration was found to be increased in the lavage of TNB induced ileitis in guinea pigs. ${ }^{8}$ In the two models of experimental colitis used in this study, the magnitude of stimulation in NOS activity is correlated with the respective increase in $\mathrm{NO}_{x}$ generation by colonic explants during 24 hours of culture. Moreover, the magnitude of the increase in colonic $\mathrm{NO}_{\mathrm{x}}$ generation and NOS activity were found to correlate with the severity of tissue damage. In TNB induced colitis, both tissue injury and $\mathrm{NO}_{\mathrm{x}}$ generation were higher than in acetic acid induced colitis. Increased NOS activity was previously reported in rats within one week after induction of colitis with $\mathrm{TNB}^{7}$ and in inflamed colonic mucosa of inflamma-

TABLE V Rat colonic $\mathrm{NO}_{\mathrm{x}}$ generation

\begin{tabular}{llll}
\hline Treatment & Lipopolysaccharide & $\begin{array}{l}\text { IFN } \gamma \\
\text { (\% of basal) }\end{array}$ & NNA \\
\hline None & $150(10)^{\star}$ & $154(20)^{\star}$ & $20(9)^{\star}$ \\
Acetic acid & $168(14)^{\star}$ & $214(25)^{\star}$ & $50(9)^{\star}$ \\
TNB & $163(11)^{\star}$ & $175(17)^{\star}$ & $77(1)^{\star}$
\end{tabular}

Colonic segments isolated from normal, acetic acid, and TNB treated rats were organ cultured for 24 hours in the presence or absence of lipopolysaccharide $(0.5 \mathrm{mg} / \mathrm{ml}), \operatorname{IFN} \gamma(10$ units/ml) or NNA $(1 \mathrm{mM})$. Basal $\mathrm{NO}_{\mathrm{x}}$ generation was 258 (27), $589(60)$, and 1705 (129) $\mu \mathrm{mol} / \mathrm{g}$ wet weight in norma untreated, acetic acid, and TNB treated rats, respectively, and was regarded as $100 \%$. Results are mean (SEM) of cultures performed with 8-15 explants obtained from 4-8 rats in each treatment group.

${ }^{\star}$ Significantly different from basal $\mathrm{NO}_{\mathrm{x}}$ generation $\mathrm{p}<0.05$.

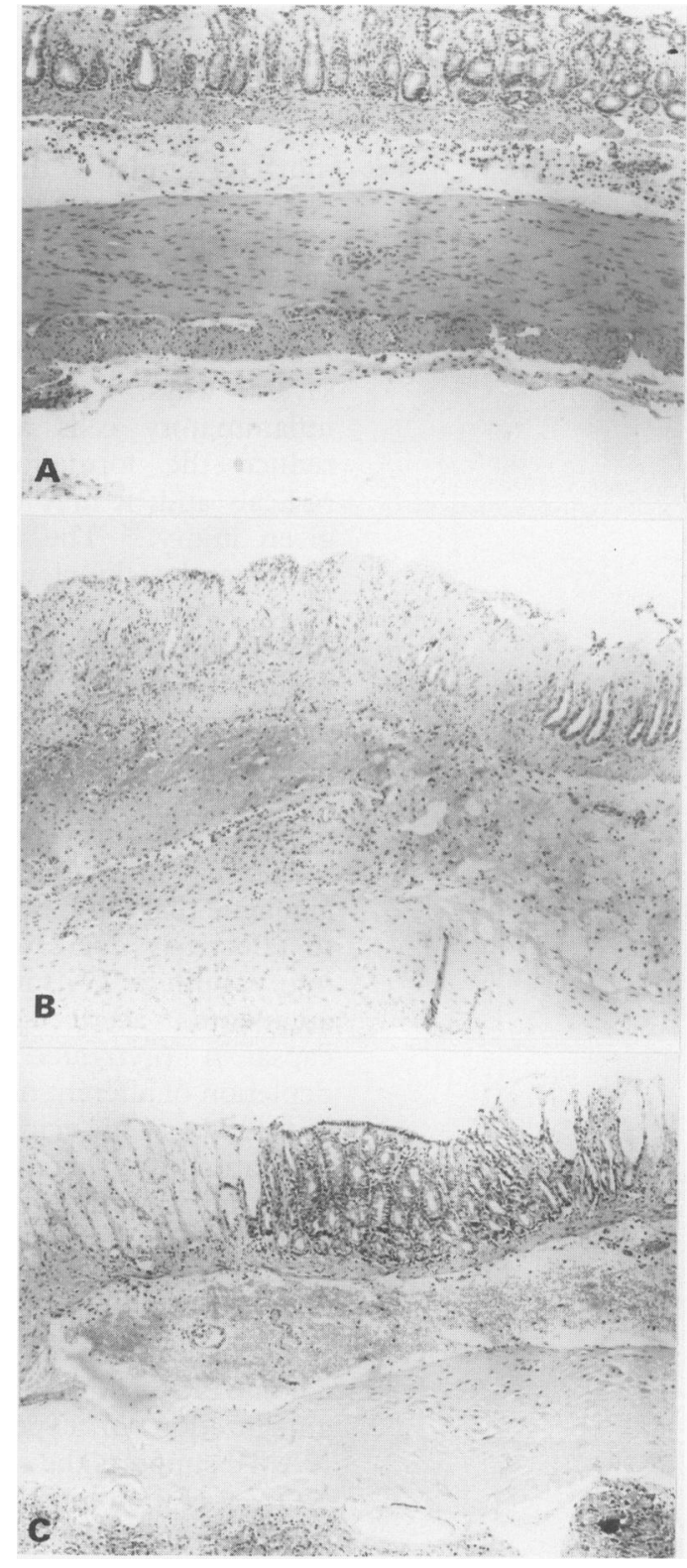

Figure 6: Histological sections of the colon isolated from acetic acid treated rats. (A) Treated with 5\% acetic acid, showing small, superficial ulcerations with a mild inflammatory infiltrate and oedema; (B) after capsaicin denervation and then treatment with $5 \%$ acetic acid, showing large, widespread, deep ulcerations with considerable inflammatory cell infiltrate involving all layers of colonic wall; $(C)$ capsaicin denervated and L-NAME treated before 5\% acetic acid administration, showing small, superficial ulcerations similar to those seen in $(A)$ rats treated only with 5\% acetic acid.

tory bowel disease patients. ${ }^{6}$ Significantly higher concentrations of citrulline were found in rectal biopsy specimens of patients with active ulcerative colitis than in those with disease in remission or in normal controls, ${ }^{25}$ further suggesting increased NO synthesis in ulcerative colitis.

Within 24 hours, L-NAME significantly increased mean arterial pressure in TNB treated rats, an effect that lasted throughout the 72 hour study period. This is consistent with other longterm studies in one of which hypertension persisted 13 weeks after the four week L-NAME treatment period had finished. ${ }^{26}$ That acute NO synthesis inhibition causes immediate rise in mean arterial pressure because of widespread vascular constriction is 
well described. ${ }^{27}$ This occurs in the renal, hindquarters, carotid and, more pertinent to this study, the mesenteric vascular beds. An acute rise in mean arterial pressure of about 40 $\mathrm{mm} \mathrm{Hg}$, similar to that seen in the TNB+LNAME treated rats herein reported, is associated with a $50 \%$ reduction in mesenteric vascular conductance. ${ }^{27}$ Such a noticeable reduction in mesenteric perfusion may affect the extent of colonic TNB induced damage in several ways: it may reduce the influx of inflammatory cells and mediators; it may reduce the formation of reactive oxygen radicals and; it may reduce the oedema of a given injury. ${ }^{28}$ The fact that NPS, an NO donor and a direct vasodilator that bypasses NOS pathways, induced complete reversal of the L-NAME protective effects on TNB induced colonic injury while the haemodynamic effects of L-NAME are only partially attenuated, strongly suggests that the LNAME protective effect cannot be attributed only to its vascular effect.

In this study, L-NAME, the L-arginine analogue that inhibits NOS activity, was found to effectively decrease the extent of colonic injury, both in TNB induced colitis and in the augmented acetic acid induced colitis in capsaicin pretreated rats. After capsaicin depletion of afferent nerve endings the damage induced by acetic acid is augmented. This augmentation was herewith shown to correlate with mucosal $\mathrm{NO}_{\mathrm{x}}$ generation and stimulated NOS activity, further suggesting the contribution of NO to the pathogenesis of mucosal injury. The protective effect of L-NAME was accompanied by a significant decrease in colonic NOS activity and $\mathrm{NO}_{\mathrm{x}}$ generation. The amelioration of experimental colitis by LNAME supports the contention that enhanced NO generation promotes mucosal injury in these two models. In a similar way, L-NAME was shown also, to ameliorate TNB induced ileitis in guinea pigs. ${ }^{8}$

In all previous studies evaluating the possible modification of gastrointestinal injury by L-NAME, the major haemodynamic changes induced by L-NAME were overlooked. In this study it is clearly shown that reduced mesenteric blood flow and decreased capillary permeability may have a certain role in the remarkable protective effect of L-NAME in TNB induced colitis.

The protective effect provided by L-NAME was accompanied by significant decrease in myeloperoxidase activity and in capsaicin augmented acetic acid induced colitis also in $\mathrm{LTB}_{4}$ and $\mathrm{LTC}_{4}$ generation. Myeloperoxidase activity is expressed in granulocytes and is a sensitive marker of the severity of colonic inflammation. ${ }^{17} \mathrm{LTB}_{4}$ and $\mathrm{LTC}_{4}$ are potent proinflammatory mediators and the lack of significant decrease in leukotriene generation in the TNB model despite the effective protection provided by L-NAME, shows that their role is probably secondary to that of NO.

The stimulation of colonic NO generation induced by lipopolysaccharide and IFN $\gamma$ points to the possible important contribution of macrophages and inflammatory neutrophils to the enhanced $\mathrm{NO}_{\mathrm{x}}$ generation detected in the inflamed colonic segments isolated from acetic acid and TNB treated rats. Endothelial cells, fibroblasts or mast cells, or all three, may also contribute to NO generation. In these cells NO generation is mainly constitutive. ${ }^{1}$ Endothelial cells, mast cells, and vascular smooth muscle cells, however, also contain the inducible isoform and, therefore, their contribution to the enhanced NO generation cannot be excluded.

Rat colonic NOS activity was found to be NADPH dependent. The L-arginine analogue, NNA, inhibited NOS activity and decreased $\mathrm{NO}_{\mathrm{x}}$ generation measured as nitrite accumulation by organ cultured explants obtained from normal and inflamed rat colonic mucosa (Tables V, VI). The inhibitory effects with this analogue at a concentration of $1 \mathrm{mM}$ may be due to an effect on the inducible, as well as the constitutive isoform, though its activity is more selective against the second. ${ }^{1}$

The protective effect of L-NAME, as shown in this study, is in contrast with findings in the upper gastrointestinal tract where NO donating substances are protective and decrease acute injury. ${ }^{29} \mathrm{NO}$ is important for organ defence. It possesses bactericidal and cytostatic properties. The increased NO generation, as herewith reported, may also represent a protective effect, as it has been shown that lipopolysaccharide induced intestinal damage is enhanced by inhibition of NO formation and decreased by NO donors. ${ }^{30}$ In extreme excess, however, it may have deleterious effects. The enhanced NO generation by the inflamed colonic mucosa may amplify the extent of tissue inflammation and injury. Enhanced generation of free NO radical species by stimulated NOS of macrophages, inflammatory neutrophils, and possibly other inflammatory cells may determine the extent and severity of the inflammatory response. Moreover, the enhanced colonic NO generation may produce carcinogenic nitrosamines shown to be generated by neutrophils during active intestinal inflammation. ${ }^{31}$ The results obtained in this study encourage the evaluation of the therapeutic effect of modulation of NOS activity as a possible therapeutic modality in patients with inflammatory bowel disease.

The excellent technical help of Mrs J Mekler is gratefully acknowledged.

1 Nathan C. Nitric oxide as a secretory product of mammalian cells. FASEB f 1992; 6: 3051-64.

2 Xie Q, Cho HJ, Calaycay J, Mumford RA, Swiderek KM, Lee TD, et al. Cloning and characterization of inducible nitric oxide synthase from mouse macrophages. Science 1992; 256: 225-8.

3 Ignarro LJ. Biosynthesis and metabolism of endothelium derived nitric oxide. Ann Rev Pharmacol Toxicol 1990; 30: 535-60.

4 Rachmilewitz D, Stamler JS, Karmeli F, Mullins ME, Singel D, Loscalzo J, et al. Peroxynitrite-induced rat colitis - a new model of colonic inflammation. Gastroenterology 1993; 105: 1681-8.

5 Rachmilewitz D, Stamler JS, Bachwich D, Karmeli F, Ackerman $\mathrm{Z}$, Loscalzo J, et al. Enhanced colonic nitric oxide generation and stimulated nitric oxide synthase activity in experimental colitis and in active inflammatory bowel disease. Gut 1995; 36: 718-23.

6 Boughton-Smith NK, Evans SM, Hawkey CJ, Cole AT, Balsitis $M$, Whittle BJR, et al. Nitric oxide synthase activity in ulcerative colitis and Crohn's disease. Lancet 1993; 342: 338-46.

7 Boughton-Smith NK, Evans SM, Whittle BJR. Elevated model of colitis [Abstract]. Gut 1992; 33 (suppl 2): S12. 
8 Miller MJS, Sadowska-Krowicka A, Chotinaruemol S, Kakkis JL, Clark DA. Amelioration of chronic ileitis by nitric oxide synthase inhibition. $f$ Pharmacol Exp Therap 1993; 264: 11-6.

9 Health and Human Services Committee. Guide for the care and use of laboratory animals. Publications 85-21, National Institutes of Health, Washington.

10 Rachmilewitz D, Simon PL, Schwartz LW, Griswold DE Fondacaro JD, Wasserman MA. Inflammatory mediators of experimental colitis in rats. Gastroenterology 1989; 97 326-37.

11 Gardiner SM, Compton AM, Bennet T, Palmer RMJ, Moncada $S$. Regional hemodynamic changes during ingestion of $\mathrm{NG}^{\mathrm{G}}$-monomethyl-L-arginine or $\mathrm{N}^{\mathrm{G}}$-nitro-Larginine methyl ester in conscious Brattleboro rats. $\mathrm{Br} \mathcal{F}$ Pharmacol 1990; 101: 10-2.

12 Martling CR. Sensory nerves containing tachykinins and cGRP in the lower airways. Acta Physiol Scand 1987; 563 (suppl): $1-57$.

13 Sharon P, Ligumsky M, Rachmilewitz D, Zor U. Role of prostaglandins in ulcerative colitis: enhanced production during active disease and inhibition by sulphasalazine. Gastroenterology 1978; 65: 638-40.

14 Stuehr DJ, Marletta MA. Mammalian nitrite biosynthesis: mouse macrophages produce nitrite and nitrate in response to Escherichia coli lipopolysaccharide. Proc Nat Acad Sci USA 1985; 82: 7738-42.

15 Bush PA, Gonzalez NE, Griscavage JM, Ignarro LJ. Nitric oxide synthase from cerebellum catalyzes the formation of equimolar quantities of nitric oxide and citrulline from L-arginine. Biochem Biophys Res Comm 1992; 185: 960-6.
Bradley PP, Priebat DA, Christensen RD, Rothstein G. Measurement of cutaneous inflammation; estimation of neutrophil content with an enzyme marker. $\mathcal{f}$ Inves Dermatol 1982; 78: 206-9.

17 Eliakim R, Karmeli F, Okon E, Rachmilewitz D. Ketotifen effectively prevents mucosal damage in experimental colitis. Gut 1992; 33: 1498-503.

18 Skaleric U, Allen JB, Smith PD, Mergenhagen SE, Wahl SM. Inhibitors of reactive oxygen intermediates suppress bacterial cell wall-induced arthritis. $\mathcal{f}$ Immunol 1991; 147: 2559-64.

19 Hibbs JB, Vavrin Z, Travitor RR. L-arginine is required for expression of the activated macrophage effector mechanism causing selective metabolic inhibition of target cells. F Immunol 1987; 138: 550-65.
20 Granger DL, Hibbs JB, Broadnax JM. Urinary nitrate secretion in relation to murine macrophage activation: influence of dietary $\mathrm{L}$-arginine and oral $\mathrm{N}^{\mathrm{G}}$-monomethylinfluence of dietary L-arginine and oral $\mathrm{N}^{-}$-m

21 Beckman JS, Beckman TW, Chen J, Marshall PA, Freeman BA. Apparent hydroxyl radical production by peroxynitrite: implications for endothelial injury from nitric oxide and superoxide. Proc Natl Acad Sci USA 1990; 87: 1620-5.

22 Zhu L, Gunn C, Beckman JS. Bactericidal activity of peroxynitrite. Arch Biochem Biophys 1992; 298: 452-7.

23 Albina JE, Abate JA, Henry WL. Nitric oxide production is required for murine resident peritoneal macrophages to suppress mitogen-stimulated T-Cell proliferation: role of $\mathrm{NNF}-\gamma$ in the induction of the nitric oxide synthesizing pathway. F Immunol 1991; 197: 144-8.

24 Yamada T, Sartor RB, Marshall S, Specian RD, Grisham MB. Mucosal injury and inflammation in a model of chronic granulomatous colitis in rats. Gastroenterology 1993; 104: 759-71.

25 Middleton SJ, Shorthouse M, Hunter JO. Increased nitric oxide synthesis in ulcerative colitis. Lancet 1993; 341 465-6.

26 Morton J, Beattie EC, Speirs A, Gullivar F. Persistent hypertension following inhibition of nitric oxide in the young Wistar rat: role of renin and vascular hypertrophy. f Hypertens 1993; 11: 1083-8.

27 Gardiner SM, Compten AM, Bennett T, Palmer RMJ, Moncada S. Control of regional blood flow by endothelium-derived nitric oxide. Hypertension 1990; 15 486-92.

28 Cotran RS, Kumar V, Robbins SL. Inflammation. In Robbins SL, ed. Pathologic basis of disease. 4th ed. Philadelphia: W B Saunders, 1989: 39-71.

29 MacNaughton WK, Cirino G, Wallace JL. Endothelium derived relaxing factor (nitric oxide) has protective action in the stomach. Life Sci 1989; 4589: 1869-76.

30 Boughton-Smith NK, Hutcheson JR, Deakin AM, Whittle BJR, Moncada S. Protective effect of S-nitroso-Nacetyl-penicillamine in endotoxin induced acute intestinal damage in the rat. Eur $f$ Pharmacol 1990; 191. 485-8.

31 Grisham MB, Ware K, Gilleland HE, Gilleland LB, Abell CL, Yamada T. Neutrophil-mediated nitrosamine formation: role of nitric oxide in rats. Gastroenterology 1992; 103: $1260-6$. 